\title{
DISCURSOS QUE PRODUZEM SENTIDOS SOBRE O ENSINO DE CIÊNCIAS NOS ANOS INICIAIS DE ESCOLARIDADE
}

Talita Vidal Pereira*

RESUMO: Neste artigo, analiso o discurso hegemônico articulado pela comunidade disciplinar que pesquisa o ensino das ciências, com o objetivo de identificar que sentidos estão sendo produzidos sobre esse ensino nos anos iniciais do ensino fundamental. Tomo como referência as produções dos dois primeiros e dos dois últimos Encontros Nacionais de Pesquisa em Educação em ciências (ENPEC), que apresentaram reflexões voltadas para esse nível de escolaridade, em um esforço para compreender o processo de constituição de um discurso que pretende hegemonicamente estabelecer o que é e o que deveria ser o ensino de ciências nos níveis elementares de escolaridade, e também estabelecer quais são as necessidades formativas para que a docência possa ser exercida nessa direção. Lanço mão da teoria do discurso de Laclau e Mouffe (2004), que me possibilita perceber esse discurso como um híbrido que circula nos diferentes contextos de produção curricular.

Palavras-chave: Ensino de Ciências; Currículo; Anos iniciais do Ensino Fundamental.

\section{SPEECHES THAT ARE MEANINGFUL TO THE TEACHING OF SCIENCES IN THE EARLY SCHOOLING YEARS}

ABSTRACT: In this article I analyze the hegemonic discourse articulated by the disciplinary communities that research the science teaching, with the goal of identifying the meanings that are being produced in the initial years of elementary school. I take as reference the productions of the two first and the two last "Encontros Nacionais de Pesquisa em Educação em Ciências" (ENPEC), that presented reflections directed towards this school level, in an effort to understand the constitution of the process of a speech that intends to establish what is and what should be science teaching in the elementary levels of school, and also to establish which the formative needs are so that teaching can be exerted in that direction. Using Laclau and Mouffe's (2004) theory of discourse, which enables me to perceive it as a hybrid discourse that pervades the different curricular contexts of production.

Keywords: Teaching of Science; Curriculum; Initial years of schooling.

* Doutora em Educação pela Universidade do Estado do Rio de Janeiro (PROPEd/UFRJ); Professora substituta na Faculdade de Educação da Universidade do Estado do Rio de Janeiro (UERJ); Bolsista da Fundação de Amparo à Pesquisa do Estado do Rio de Janeiro (FAPERJ). E-mail: p.talitavidal@gmail.com 
Este trabalho tem por base a investigação em curso no doutoramento cujo foco são os processos de constituição do saber ensinado nas aulas de ciências naturais nos anos iniciais do Ensino Fundamental (EF). No decorrer do estudo surgiu a necessidade de identificar que sentidos estão sendo atribuídos ao ensino de ciências naturais (ECN) nos níveis mais elementares de escolaridade. Essa percepção se consolidou na medida em que foram identificados, nas falas das professoras ${ }^{1}$ dos anos iniciais, elementos presentes nos discursos das comunidades epistêmicas sobre o que é e sobre como deveria ser o ECN nesse nível.

A categoria comunidade epistêmica tem sido utilizada por Stephen Ball (2001) para analisar a participação de sujeitos e grupos sociais com reconhecida autoridade no campo na constituição e difusão de discursos curriculares, a partir das posições que ocupam nos diferentes contextos de produção de políticas curriculares. Segundo Dias (2009), as comunidades epistêmicas se constituem a partir da formulação e dos encaminhamentos de demandas como "uma rede de sujeitos e grupos sociais que participam da produção, circulação e disseminação de textos que constituem as políticas curriculares nos contextos de influência e definição de textos" (p. 13).

Essa definição foi tomada como referência em função da compreensão de que os processos de produção da política curricular para o ECN estão implicados nas articulações em torno de demandas formuladas e difundidas pelos diferentes sujeitos e grupos sociais que constituem as comunidades epistêmicas das ciências naturais. Sujeitos e grupos que atuam em rede ocupando diferentes posições nos diferentes contextos de produção de políticas (BOWE et al., 1992) ${ }^{2}$ e produzindo discursos curriculares que visam a se constituir hegemônicos (LACLAU, 1998; 2001; 2005; 2006).

Dias (2009) afirma que a circulação intensa dos discursos produzidos pelas comunidades epistêmicas é garantida por meio de publicação de livros, participação em congressos, realização de consultorias, desenvolvimento de atividades de capacitação. Essas ações conferem e sustentam a autoridade que determina a influência que exercem sobre a formulação de políticas, quando são chamadas a constituir comissões, consultorias e conselhos envolvidos na elaboração de documentos curriculares. Por outro lado, sua presença também se faz no contexto da prática, a partir das vinculações dos sujeitos com seu espaço de trabalho (BALL, 1994). 
É possível perceber que essas comunidades exercem forte influência na configuração das disciplinas escolares, entendidas como resultado de um processo dinâmico de construção social, em que são determinantes os fatores de natureza interna, que dizem respeito diretamente ao saber de referência, aos critérios epistemológicos, bem como aos interesses diversos das comunidades científicas e disciplinares, e que inclui a obtenção de financiamentos indispensáveis para a continuidade de suas pesquisas. Também por fatores externos, que dizem respeito às demandas provenientes da dinâmica social, política e econômica (LOPES, 1999). Esses fatores são mutuamente influenciados.

Por outro lado, na investigação em curso, o currículo é concebido como espaço-tempo em que são produzidos sentidos que constituem o saber ensinado e aprendido. Portanto, trata-se de produções culturais que resultam dos processos de hibridização de diferentes registros culturais e envolvem "significados construídos na relação da tradição com as novas ações discursivas presentes nos múltiplos contextos" (BARREIROS, 2009, p. 44). Isso implica assumir que a constituição de uma disciplina escolar não se limita aos processos de embate entre as comunidades epistêmicas. Os consensos produzidos são provisórios e a disciplina permanece se reconfigurando no contexto da prática, o foco principal da tese de doutoramento.

Nessa perspectiva, as políticas curriculares são concebidas como discurso, assumido como categoria teórica que permite investigar os mecanismos pelos quais os sentidos são produzidos e como conferem orientação aos fenômenos sociais. Não uma orientação predeterminada, mas que se produz e se transforma na própria dinâmica discursiva (LACLAU, 2001).

Para Laclau, discurso não é fala, mas campo de práticas. Uma "unidade complexa de palavras e ações de elementos explícitos e implícitos, de estratégias conscientes e inconscientes. É parte inseparável da ontologia social dos objetos" ( BURITY, 2008, p. 42). Assim, conceber currículo como discurso produtor de sentidos permite romper com a lógica que o assume como texto produzido em uma instância central e imposto ao contexto da prática, verticalização combatida por Bowe e seus colaboradores (1992).

Os dinamismos, a provisoriedade e a contingencialidade de um discurso resultam das tentativas de fixação dos sentidos que ele carrega e 
que podem possibilitar sua hegemonização. No entanto, Laclau e Mouffe (2004) argumentam que esse objetivo nunca poderá ser concretizado, dada uma dupla impossibilidade. A primeira diz respeito ao antagonismo existente entre sistemas discursivos diferentes. O corte antagônico constitui uma fronteira que impede a completa proliferação de sentidos em uma cadeia de equivalência. A segunda decorre da proliferação de sentidos no interior de uma formação discursiva, que é condição para sua universalização. A "abundância de sentidos que podem ser incorporados, constituídos ou perdidos por um discurso impedem a sua completa fixação" (MENDONÇA, 2003, p. 143).

Laclau e Mouffe explicam a constituição de um discurso como resultado da articulação de diferentes demandas, que, em um primeiro momento, estão dispersas no campo da discursividade e passam a ser ordenadas em uma cadeia de equivalência. Esse ordenamento acontece em torno de pontos nodais e, a partir deles, os elementos passam a se constituir em momentos, que são definidos pelos autores como elementos equivalentes.

É nessa perspectiva que Laclau (1998) justifica o processo de constituição de hegemonia como uma operação discursiva que busca articular demandas em uma cadeia de equivalência. Dessa forma, para Laclau, a hegemonia é entendida como uma operação discursiva que apontará permanentemente para tentativas de recomposição e rearticulação na direção de superar a impossibilidade da totalidade. No entanto, a direção dessa tentativa não está dada anteriormente ao processo. Não é algo a ser revelado ou descoberto, mas uma construção, que acontece em meio às disputas incessantes pelo poder, em que diferentes discursos tentam se impor. Portanto, a constituição de hegemonia nada mais é do que a tentativa de apresentar um desses discursos como capaz de encerrar um sentido que contemple os demais. Ou seja, sua capacidade de articular diferentes demandas.

Laclau e Mouffe (2004) entendem que a articulação das demandas acontece em função de um exterior constitutivo, um elemento que é expulso da cadeia de equivalência e possibilita que demandas diferenciadas possam abrir mão de seus conteúdos particulares. É o exterior constitutivo, o inimigo comum, que torna possível os processos de identificação em uma cadeia de equivalência. Ele expressa os traços da exclusão que tornam possível a diferenciação entre formações discursivas diferentes. 
Assim, segundo esses autores, a articulação de diferentes demandas só é possível pela constituição de pontos nodais que passam a expressar um sentido comum entre elas. É esse sentido que é apreendido como comum que confere equivalência entre os elementos diferentes, transformando-os em elementos equivalentes ou momentos (MENDONÇA, 2003). No entanto, Laclau e Mouffe (2004) alertam que um momento sempre guarda referência ao elemento que o originou, por isso mantém uma particularidade que impede que, em uma cadeia de equivalência, se iguale aos outros. Daí afirmarem que o consenso hegemônico é sempre provisório e marcado pela precariedade e pela contingência.

É dessa forma que podemos compreender como a proliferação de sentidos, necessária à constituição de hegemonia, impede o completo fechamento/fixação de sentidos de um discurso.

Assim, pensar o currículo como discurso nessa perspectiva possibilita apreendê-lo como processo de produção de sentidos, inclusive no contexto da prática (BOWE et al., 1992). Possibilita também compreender a constituição de uma disciplina escolar como movimento dinâmico em que estão envolvidos múltiplos interesses. No caso específico da disciplina ciências naturais, essa complexidade assume ainda outra dimensão. Afinal, essa disciplina se caracteriza pela tentativa de integração de diferentes disciplinas de referência acadêmica e científica (WORTMANN, 1998; LOPES, 2008), estando, portanto, sujeita às influências de diferentes campos do conhecimento, que, para além das especificidades das ciências da natureza, incluem também o campo educacional, o que, no que diz respeito ao ECN, assume destaque especial, orientando investimentos em políticas específicas (KRASILCHIK, 2000).

Essas diferentes tendências são assumidas como demandas articuladas pelos discursos que buscam fixar uma única compreensão do que é e do que deveria ser o ECN. São esses sentidos que passam a orientar análises e avaliações sobre o ensino realizado nas aulas de ciências naturais, em geral fundamentadas em uma concepção objetivada de currículo, entendido como texto/proposta a ser executado pela escola.

São estes os pressupostos que fundamentam a caracterização do discurso que busca se se constituir como hegemônico, que procura fixar sentidos sobre o que é e o que deveria ser o ECN nos anos iniciais do EF. Discurso que circula pelos diferentes contextos de produção curricular (BOWE et al., 1992), inclusive no contexto da prática, mesmo em um 
nível de ensino que se caracteriza por um modelo didático-pedagógico de caráter generalista, em que a regência da turma é assumida por um único(a) professor(a), portador(a) de uma formação geral capaz de articular as noções básicas de diferentes áreas do conhecimento e que, pelo menos supostamente, deveria estar menos sujeito(a) às pressões disciplinares.

\section{Definindo os marcos da análise}

$\mathrm{Na}$ investigação em curso, são analisados os anais dos Encontros Nacionais de Pesquisa em Educação em Ciências (ENPEC). A partir deles, foram selecionados trabalhos que apresentam reflexões voltadas para o nível de escolaridade desejado, indicando o diagnóstico dos autores, que justificam as mudanças que sugerem como as mais apropriadas para que se realize uma educação científica de qualidade.

Com base nesses trabalhos são identificadas as demandas que caracterizam o discurso produzido pela comunidade disciplinar que pesquisa o ensino de ciências, assumindo que vários grupos e sujeitos que atuam na Associação Brasileira de Pesquisa em Educação em Ciências, entidade que bianualmente, desde 1997, promove o ENPEC, integram a comunidade epistêmica e exercem influência nas políticas curriculares para o ECN. Alguns dos textos analisados apresentam resultados de intervenções curriculares realizadas em diferentes redes de ensino e contam com financiamento de diferentes agências. A escolha pelas produções dos ENPECs se deu pela importância desse evento no campo da pesquisa em educação em ciências.

Neste artigo, são apresentados alguns resultados obtidos a partir de um levantamento que implicou a seleção de 71 produções, identificadas a partir da análise de palavras-chave, título, resumo e, em alguns casos, da introdução do artigo, que evidenciasse que o trabalho abordava, de alguma maneira, o ensino de ciências nos anos iniciais do EF.

O levantamento começou pelo último Encontro, o VII ENPEC, realizado na cidade de Florianópolis, em 2009. A escolha se deu em função da facilidade de acesso aos anais, disponibilizados na internet ${ }^{3}$. Utilizando os critérios de seleção já mencionados, foi possível selecionar 21 trabalhos de um total de 693. Também foi possível identificar um grau 
elevado de saturação do discurso, com alguns elementos recorrentes. Essa constatação foi fundamental para a reorientação do estudo. A partir dela, foram focados os dois últimos e os dois primeiros ENPECs. Sendo assim, foi analisado um total de 71 trabalhos. Além dos 21 já citados, sete entre 139 do I ENPEC, 13 entre 117 do II ENPEC e 30 entre 601 do VI ENPEC.

Para organizar a análise, os trabalhos selecionados foram separados em três grandes blocos. Um que contempla os diferentes tipos de levantamentos que apresentassem dados referentes ao ensino de ciências nos anos iniciais, em um total de seis textos completos e um resumo. Outro que reúne os artigos voltados para a formação docente, em um total de 21 trabalhos, entre textos completos e resumos. E, por fim, o terceiro bloco, com trabalhos voltados para metodologias, recursos e temáticas específicas, em um total de 32, também entre textos e resumos.

Embora essa classificação tenha sido necessária para iniciar a análise, ao longo dela foi possível identificar que os trabalhos reunidos no grupo três a apresentação de propostas que visam à melhoria do ensino realizado também remetem a uma avaliação insatisfatória da formação docente. Fazendo ou não referências explícitas à formação, alguns dos textos selecionados relatam experiências que envolvem abordagens metodológicas, utilização de recursos variados ou tratamento referente a um assunto específico, que, segundo os autores, pode contribuir para a superação das dificuldades e inseguranças das docentes nas situações de ensino. A prescrição parece ser uma marca nesses trabalhos e mesmo estudos que se propõem discutir a natureza do conhecimento científico, como o realizado por Longhini e Mora (2009), não escapam dessa lógica, quando sugerem uma abordagem capaz de contribuir para a superação de uma compreensão "deformada" (aspas minhas) dos conhecimentos científicos.

Sete trabalhos foram fundamentais, por serem levantamentos das produções do campo. Eles apresentam resultados que também foram encontrados no presente estudo.

No primeiro ENPEC, foi publicado um resumo do levantamento realizado por Mendes Sobrinho (1997) sobre aspectos históricos do ensino de ciências no curso de magistério. Por se tratar de um resumo, não foi possível colher muitas informações sobre a problematização ou o tratamento dado ao autor na análise dos dados. 
Em 1999, Megid Neto descreveu e analisou as principais características e tendências da pesquisa acadêmica sobre o ECN no Brasil, representada pelo conjunto de teses e dissertações defendidas entre 1972 e 1995, com foco na educação científica, em suas diversas modalidades curriculares e níveis de escolarização. O autor focaliza 212 trabalhos voltados para o EF, sendo 45 deles direcionados aos anos iniciais.

Em dois aspectos, os resultados do presente estudo coincidem com os apresentados por Megid Neto em 1999. O primeiro diz respeito ao número ainda insuficiente de pesquisas (71 em um total de 1550) voltadas especificamente para o ECN nos anos iniciais de escolaridade. $\mathrm{O}$ segundo tem a ver com a centralidade que as abordagens metodológicas e/ou a utilização de recursos assume nos trabalhos. Quanto a esse último aspecto, Megid Neto afirma que identificou uma tendência dessas produções a ficarem restritas à dinâmica do processo de aprendizagem, sem apontar alternativas para um ensino mais contextualizado e menos fragmentado. $\mathrm{Na}$ investigação objeto deste artigo, foi possível identificar uma tendência de superação desse quadro, quando comparamos as produções dos primeiros aos últimos ENPECs. Menos no que se refere ao aspecto quantitativo, e ainda mais na ênfase à defesa de um ensino contextualizado, capaz de atender às demandas de uma formação cultural e cidadã (BASTOS, 2009).

A análise evidencia que os trabalhos voltados para a problemática ambiental (CARNEIRO; ARAÚJO; OLIVEIRA, 2008; BACCI, 2008) e aqueles que apontam para a necessidade de uma educação científica em uma perspectiva de letramento (PAVAN; BRASIL; TERRAZZAN, 2008; OLIVEIRA et al., 2008) incorporam uma contextualização segundo a qual o ensino deve ser pensado e realizado de forma articulada, com aspectos que extrapolem os limites restritos de situações específicas da sala de aula ou da escola.

Nos anais do Encontro realizado em 2007, foi possível selecionar o levantamento bibliográfico apresentado por Azevedo, Ghendin e Gonzaga (2008) ${ }^{4}$, em que os autores também constatam um número insuficiente de trabalhos voltados para o ECN nos anos iniciais de escolaridade. Nesse trabalho, os autores não informam suas fontes privilegiadas, mas pelas referências apresentadas é possível presumir que buscaram na literatura fontes diversificadas: artigos, livros, relatos de pesquisa, etc. Eles afirmam que a formação das professoras é um fator determinante para o 
ensino inadequado, mas destacam que não se trata de uma característica exclusiva das séries iniciais. Segundo eles, a formação docente não tem privilegiado o necessário processo de reflexão sobre a prática que permita alterá-las e criticam o modelo de formação pautado pela racionalidade técnica como obstáculo à mudança. Recorrem a uma pesquisa realizada por Almeida et al. (2001) 5 com 200 professoras dos anos iniciais do EF da rede municipal do Recife para confirmar essa situação, que, segundo eles, revela os limites da prática docente e, consequentemente, de sua formação no âmbito do ECN, dado que as concepções das professoras apresentam forte marca empirista/positivista que se reflete em suas práticas. Afirmam que é muito presente, nos discursos, a crença de que o ECN não pode prescindir das atividades de laboratório. No entanto, em geral, as atividades são concebidas como elementos motivadores da aprendizagem, como suporte, perdendo seu potencial como situações problematizadoras e desafiantes para as crianças.

Em alguns dos trabalhos analisados, os autores apontam necessidades formativas das docentes que podem atender às novas exigências impostas pela sociedade e pela realidade escolar. Defendem que o domínio dos conteúdos científicos também implica a compreensão de aspectos epistemológicos e históricos que podem permitir que as professoras explorem nas situações de ensino, as relações entre ciência, tecnologia e o contexto social, econômico e político, apontando para um ensino mais contextualizado.

Afirmam também a necessidade de investimento em um modelo de formação inicial e continuada que possibilite a superação de visões simplistas do processo pedagógico de ECN, usualmente centradas no modelo transmissão-recepção e em uma concepção empiricista-positivista de ciência. Afirmam que a docência pressupõe o exercício de uma prática reflexiva, resultado de uma articulação teoria-prática.

Portela e Higa (2008) também apresentaram um levantamento sobre as tendências para o ensino de Física nos ciclos iniciais do EF, a partir da análise de trabalhos publicados em quatro periódicos nacionais a partir de 1994, a saber: Caderno Brasileiro de Ensino de Física, Investigações em Ensino de Ciências, Ciência \& Educação e Ensaio Pesquisa em Educação em Ciências.

Para defender a importância do ECN nos anos iniciais, as autoras fazem referência aos avanços científicos e tecnológicos e à necessida- 
de de promover a alfabetização científica das crianças e jovens. Nessa perspectiva, defendem a importância do ensino de Física, que, segundo elas, não recebe o devido destaque nesse nível de ensino. Essa observação também é feita em outros cinco trabalhos que abordam o ensino de conceitos físicos, três dos quais defendem mais espaço no currículo dos anos iniciais para o ensino dos conceitos químicos e três que procuram investigar como os conteúdos relativos à astronomia estão sendo contemplados nas aulas de ciências.

Esses trabalhos remetem a uma consideração importante sobre a constituição de discursos híbridos na produção de currículos, pois, ao mesmo tempo em que a interdisciplinaridade tem ganhado destaque no discurso educacional, se afirmando como uma perspectiva de organização curricular bem-aceita no meio acadêmico (ZIBAS, 2005), permanecem as disputas entre diferentes campos disciplinares por maior espaço no currículo. Essas demandas disciplinares específicas são articuladas no mesmo discurso, que afirma a necessidade de um ensino mais contextualizado e menos fragmentado, expressando uma ambiguidade do mesmo.

Ainda nos anais de 2007, Pavan, Brasil e Terrazzan (2008) apresentaram os resultados de sua investigação sobre a produção dos cinco ENPECs realizados anteriormente com foco no ensino de ciências para crianças. Os autores procuraram identificar o tratamento dado à temática da alfabetização científica e tecnológica.

Um aspecto que evidencia a circulação do discurso pelos diferentes contextos de produção das políticas curriculares (BOWE et al., 1992) é a constante referência que os autores de diferentes trabalhos fazem ao texto dos parâmetros curriculares nacionais (PCN-Ciências) para sustentar suas argumentações. Essa recorrência também fornece pistas sobre a concepção verticalizada de currículo que orienta as produções, na medida em que os parâmetros são apresentados como exemplo de uma boa proposta que não se concretizaria no espaço da sala de aula.

Pavan, Brasil e Terrazzan (2008), por exemplo, citam o texto em questão para defender que a formação do cidadão crítico passa pelo tratamento dos assuntos científicos relacionados ao cotidiano dos alunos, daí a importância de uma educação tecnológica que favoreça a alfabetização científica desde os anos iniciais do EF. Essa referência é feita sem qualquer problematização às ambiguidades presentes no texto curricular oficial. Como se ele fosse a expressão de um pensamento homogêneo, e não 
resultado de um processo de disputa entre diferentes atores e grupos envolvidos, como já analisaram Moreira (1996) e Lopes (2004), entre outros.

Rocha e Megid Neto (2009) apresentam os resultados de um levantamento feito em periódicos científicos nacionais e estrangeiros com o objetivo de identificar e descrever práticas de formação inicial e continuada de professoras para o ECN. Os autores afirmam a necessidade de realizar um estudo aprofundado com essa temática com o objetivo de recolher subsídios que possam auxiliar na formulação de políticas educacionais que possam contribuir para a superação dos obstáculos que impedem a realização de uma educação científica de qualidade nos níveis mais elementares de ensino.

Os autores esclarecem que, nos artigos que analisaram, aparecem sugestões de medidas que podem ser concretizadas nos cursos de formação inicial de professores, em especial nos cursos de Pedagogia ou em cursos de formação continuada. O pressuposto é que os/as docentes não recebem formação científica adequada, por isso não conseguem viabilizar as diferentes propostas voltadas para a melhoria do ECN, comprometendo sua qualidade.

Dando continuidade a um trabalho apresentado no ENPEC de 1999, citado acima, Megid Neto, em coautoria com Fernandes, apresentaram, em 2009, um novo trabalho em que identificaram as características e tendências pedagógicas das práticas escolares propostas e implementadas em teses e dissertações direcionadas ao ECN nas séries iniciais do EF, no período de 1972 a 2005. Na análise de 30 trabalhos, os autores identificaram o tratamento dado ao método de ensino, aos recursos didáticos, à relação professor-aluno, à avaliação, ao referencial teórico e ao modelo educacional e concluíram pela predominância do modelo construtivista, seguido do sociocultural e da redescoberta. Mais uma vez aparece uma convergência entre os resultados dos autores e os do estudo aqui apresentado.

Nos trabalhos dos ENPECs analisados neste estudo (FERREIRA JÚNIOR et al., 2008; RAZERA et al., 1999; FERNANDES; MEGID NETO, 2009; PORTELA; HIGA, 2008; SILVA; MARCONDES, 2008; BASTOS, 2009), entre outros, foi possível identificar a predominância significativa do modelo construtivista, evidenciada pela referência à importância dos conhecimentos prévios como ponto de partida para o proces- 
so de mudança conceitual. Com relação a esse aspecto, via de regra, os trabalhos alertam para as dificuldades de promover mudanças nas concepções docentes que possibilitem o desenvolvimento de práticas alternativas e inovadoras nas aulas de ciências dos anos iniciais do EF, e também fica evidenciada uma concepção objetivada de currículo como uma proposta ou prescrição a ser implementada no contexto da prática.

Por outro lado, Fernandes e Megid Neto (2009) também chamam a atenção para outro aspecto importante a ser considerado que diz respeito à relação hierárquica estabelecida entre pesquisadores, docentes e alunos(as). Os autores destacam que os trabalhos analisados por eles indicam que os pesquisadores não encontram dificuldades em aplicar suas propostas, no entanto, elas parecem não produzir as mudanças desejadas, principalmente com relação às mudanças nas relações pessoais, com o/a docente assumindo outra postura frente aos alunos e alunas e nas formas de avaliar o ensino e a aprendizagem. Com base nisso, concluem que a tendência é que se estabeleça uma postura verticalizada na relação pesquisador-professor, que tende a acentuar a relação autoritária entre universidade e escola, que também acaba por se refletir na postura que o professor assume frente aos seus alunos. Dessa forma, concluem que, embora nos trabalhos, em nível de discurso, seja enfatizada a necessidade de compartilhar ideias, estabelecendo uma relação dialógica, essa relação não se concretiza no âmbito da pesquisa e não contribuí para mudanças no relacionamento professor-aluno.

O aspecto desenvolvido pelos autores é importante, mas na perspectiva teórica aqui desenvolvida não pode ser entendido apenas como mera resistência devido a uma relação hierárquica autoritária. O entendimento do currículo como espaço-tempo de produção de sentido permite incorporar esse sentimento de resistência e ir além, entendendo que é impossível fixar completamente qualquer sentido e que isso não é demérito da proposta ou da prática. Faz parte da dinâmica discursiva em que são atribuídos significados ao mundo.

Todos esses levantamentos apresentados nos diferentes ENPECs apontam tendências que se confirmaram na análise dos trabalhos selecionados a partir dos anais dos encontros no período de 12 anos que separam o primeiro e o sétimo ENPEC. Essa análise permite afirmar a existência de um discurso que se pretende constituir como hegemônico e se articula com o objetivo de fixar sentidos sobre o que é ou deveria ser 
o ECN. Isso se evidencia menos em relação ao número de trabalhos e mais no que diz respeito à multiplicidade de abordagens e temáticas desenvolvidas.

\section{Caracterizando o discurso híbrido que circula nas produções dos ENPECs}

Segundo Laclau e Mouffe (2004), a hegemonia de um discurso se constitui em função de um exterior constitutivo. É esse inimigo comum que torna possível a articulação de demandas diferenciadas em uma cadeia de equivalências. No discurso em questão, esse exterior constitutivo pode ser entendido como o ensino de qualidade ruim a ser superado para que se possa alcançar uma educação de qualidade, entendida como um significante vazio, dados os múltiplos sentidos que a ela são atribuídos (LACLAU, 2001). Esse inimigo externo fica bem-caracterizado no diagnóstico que os trabalhos apresentam sobre o ECN nas classes dos anos iniciais do EF. Trinta e um dos trabalhos analisados caracterizam esse ensino como ineficiente e incapaz de atender às demandas postas pelo mundo contemporâneo.

Esses autores fazem referência aos níveis elevados do avanço tecnológico, em especial da informática, que altera profundamente os processos de trabalho, determinando a intensificação dos processos de automação, que, por sua vez, alteram a dinâmica social. Esse discurso reafirma os ideais da educação moderna ao apresentar a apropriação do saber científico e tecnológico como condição para desenvolvimento das pessoas e das nações, estabelecendo uma relação direta entre a formação cidadã e a educação científica e tecnológica, que, segundo os autores, deve ser iniciada o mais cedo possível.

Sacristán (1999) alerta se tratar de um sentimento de fé a priori na educação e, é possível acrescentar, nas possibilidades da ciência, que, mesmo questionada nos marcos da crítica aos pressupostos da modernidade, permanece recontextualizada em um discurso híbrido (MACEDO, 2003; LOPES, 2005; 2008).

Caracterizado o inimigo externo, os diferentes trabalhos passam então a apresentar suas propostas - demandas - que, segundo eles, podem contribuir para a superação do problema, possibilitando uma educação de qualidade, que favorece a articulação de demandas diferenciadas e que 
pode ser assumida como uma tentativa de preencher e fixar sentidos atribuídos à qualidade.

É o que acontece, por exemplo, em relação à defesa da necessidade de maiores investimentos em educação científica, apresentada como condição essencial à formação cidadã. Leal e Gouvêa (1999) apresentam um breve retrospecto do movimento Ciência, Tecnologia e Sociedade (CTS), situando polêmicas em torno do tema. As autoras defendem a "apropriação do conhecimento científico como elemento importante na capacitação do sujeito para o pleno exercício de sua cidadania” (p. 4). Para elas, a educação científica não deve ser apenas o entender como a ciência funciona, mas também contemplar um posicionamento crítico frente às relações entre desenvolvimento científico e tecnológico e desenvolvimento social.

Por sua vez, Sasseron e Carvalho (2008) procuram problematizar as concepções de alfabetização científica, apresentando o que entendem ser os três principais aspectos para caracterizá-la:

o entendimento das relações existentes entre ciência, tecnologia, sociedade e, mais recentemente, meio-ambiente; a compreensão da natureza da ciência e dos fatores éticos e políticos que circundam sua prática e a compreensão básica de termos e conceitos científicos fundamentais. (p. 4)

As autoras defendem a necessidade de investimento na formação de uma cultura científica e tecnológica. Destacando que, nos documentos da Unesco, o termo inglês literacy é traduzido pela palavra "cultura", elas justificam a utilização do termo alfabetização científica, atribuindo a ele o sentido de enculturação e letramento científico, que, segundo defendem, deve ser iniciada desde o início da escolarização, permitindo que alunos e alunas trabalhem ativamente no processo de construção do conhecimento e debatam questões que aflijam sua realidade. Com isso, Sasseron e Carvalho entendem que crianças podem ser introduzidas em uma cultura científica desde que possam estudar temas científicos utilizando as ferramentas culturais adequadas.

A ideia de enculturação pressupõe a existência de uma cultura específica - a científica -, na qual professores e professoras e, por consequência, alunos e alunas, seriam introduzidos ao processo de ensino. Nesse sentido, apresentam uma concepção reificada de cultura - e de currículo -, em que a alfabetização científica implica um processo de encul- 
turação, em que uma cultura objetivada deve ser transmitida pela escola e apropriada pelos estudantes.

Esclarecendo que não se trata de formar futuros cientistas, Sasseron e Carvalho (2008) defendem uma proposta de ensino desenvolvida por meio de estratégias argumentativas em que situações-problemas, ligadas às problemáticas referentes as relações CTS, sejam apresentadas aos estudantes, que devem, a partir delas, formular hipóteses visando a solucioná-las. A defesa da argumentação como estratégia de ensino se dá em uma perspectiva linguística, e não em uma perspectiva discursiva, em sintonia com a proposta de letramento científico, concepção de alfabetização científica que aparece com destaque na literatura sobre o tema.

Em outro trabalho, Veraszto et al. (2008) afirmam que, embora a inserção da tecnologia seja tida como um elemento de inovação curricular, ainda são em número insuficiente as iniciativas concretas em sala de aula destinadas a colocar o aluno diante da mesma. Para os autores, o que se observa é a possibilidade de contatos dos estudantes com produtos tecnológicos de ponta fabricados para fins comerciais, fazendo com que eles aprendam a operacionalizá-los ou sobre o seu funcionamento. Os autores também alertam que existe uma tendência de conceber a tecnologia como mera aplicação prática de conceitos científicos e matemáticos, em que alunos e alunas são incentivados a simplesmente repetir experiências abordadas por manuais, o que, segundo eles, não pode, por si só, ser caracterizado como uma verdadeira educação tecnológica.

Bizerra et al. (2009) também destacam a ausência de consenso em torno de uma concepção de alfabetização científica, destacando que ela tanto pode expressar a condição de um sujeito capaz de identificar processos que caracterizam a produção científica e perceber as relações entre ciência e sociedade quanto se restringir a definição de conteúdos básicos que a população sabe ou deveria saber sobre ciência.

Embora esses trabalhos alertem para a necessidade de caracterizar o conceito de alfabetização científica demarcando diferenças entre uma educação científica que não leva em conta sua dimensão social em uma perspectiva crítica, não há nenhuma referência ou questionamento à lógica que estabelece uma ligação direta entre a educação científica e o exercício pleno da cidadania. A apropriação da ciência e da tecnologia, ainda que ressignificada, continua sendo difundida como condição essencial para o desenvolvimento e para superação das desigualdades sociais 
entre pessoas e países. A educação científica é apresentada como condição essencial para que essa superação aconteça.

A marca da ambiguidade desse discurso pode ser percebida no trabalho de Versuti-Stoque e Lopes Júnior (2009). Nele, os autores afirmam que a importância de desenvolver os conteúdos científicos desde os anos iniciais DO EF se reforça na medida em que, para grande parcela da população, essa é a única experiência de escolaridade.

Ou seja, mesmo considerando que uma discussão sobre a lógica excludente do sistema educacional brasileiro não é o objeto de estudo dos autores, parece que essa referência torna explícita a ambiguidade da concepção de cidadania defendida por eles. Se a oportunidade de acesso à escola é um dos pilares da igualdade democrática, na lógica defendida pelos autores, a educação científica, por si só, não pode garantir o exercício pleno da cidadania, se o acesso e a permanência dos sujeitos na escola não estão garantidos.

Macedo (2008) apresenta algumas considerações interessantes sobre a ambivalência dos discursos em defesa de uma formação cidadã. A autora problematiza a ideia de cidadão como elemento presente nas enunciações curriculares das últimas décadas no Brasil e em diversas partes do mundo. Ela afirma que o conceito de cidadania desliza carregando múltiplos significados nos discursos educacionais e, nesses deslizamentos, ora é enfatizado o caráter público da educação, ora ela é tratada como bem privado (MACEDO, 2008).

A autora procura entender de que forma essas diferentes concepções se articulam discursivamente construindo "novos modos de endereçamento [...] que se constituirão como novos textos (poderosos, na medida em que institucionalizados) a serem utilizados nos enunciados curriculares de cada um" (MACEDO, 2008, p. 98). E conclui que, nesses novos enunciados, a ideia de cidadania tende a ficar reduzida a um conjunto de conteúdos nas disciplinas sociais (MACEDO, 2000).

Não é possível afirmar que seja o caso dos textos analisados, no entanto, isso só reforça a necessidade de reflexão mais radical sobre os múltiplos sentidos que circulam nos discursos, assumindo que a universalidade atribuída a um único significado de cidadania nada mais é do que o resultado de uma operação discursiva (LACLAU; MOUFFE, 2004). A compreensão dessa dinâmica é fundamental para a apreensão dos mecanismos de funcionamento da política nos diferentes contextos de produção. 
Dando prosseguimento à caracterização do discurso híbrido sobre o ECN, é possível destacar, como afirma Pereira (2010), a importância que o discurso educacional dominante atribui à ciência e à tecnologia como elementos propulsores do progresso, concebido como o alcance de determinados níveis de desenvolvimento econômico e dos sujeitos. Se, como explicita a autora, essa é uma marca do processo de escolarização na modernidade, no discurso educacional contemporâneo essa ideia se expressa em um movimento de recontextualização do discurso que pretende renovar o otimismo epistemológico sobre as possibilidades da ciência.

Aqui, mais uma vez, surgem ambiguidades, afinal, como foi destacado anteriormente, a grande maioria dos trabalhos se inscreve em uma perspectiva construtivista, considerando fundamental o conhecimento de concepções prévias, alternativas, espontâneas - as designações são usadas indiscriminadamente - como ponto de partida para o desenvolvimento de um trabalho, com alunos(as) e/ou com professoras, que favoreça a mudança conceitual.

Zanon e Cardinal (1999), investigando como o tema da cárie dentária é explorado em uma turma de quarta série ${ }^{6}$ do EF, ressaltam a importância e a relevância social da ciência e reconhecem que as professoras têm se mostrado empenhadas em realizar uma abordagem contextualizada. Contudo, entendem que, por não dominarem os conteúdos, não conseguem oferecer um ensino que privilegie a atenção às características dos materiais e substâncias e suas transformações no contexto da vida. Dessa forma, concluem que, embora apresente aspectos positivos, como a maior compreensão por parte das crianças dos benefícios e dos cuidados com a prevenção, o ensino não favorece a iniciação ao estudo da química nos anos posteriores de escolaridade.

Aqui é importante notar se a complexidade que envolve o processo de ensino nos anos iniciais de escolaridade, inclusive na condição específica do professor(a) generalista habilitado para exercer a docência nos anos iniciais do EF, foi levada em conta na avaliação das autoras. Como, por exemplo, uma reflexão sobre os objetivos estabelecidos. Se o objetivo era uma educação preventiva contra a cárie, ela não pode ser considerada de sucesso? Em que medida o domínio do conceito de substância garantiria a formação de hábitos de prevenção? Cabe indagar em que medida o estabelecimento dessa relação direta é feita a partir do privilégio 
epistemológico atribuído ao conhecimento científico, cuja apropriação garantiria aos sujeitos, no entender das autoras, tomar decisões melhores e mais racionais.

Brando, Andrade e Marques (2007), analisando o trabalho desenvolvido por professoras da educação infantil sobre o tema alimentação, concluem que a formação insuficiente não permite que seja desenvolvido um ensino contextualizado e interdisciplinar em que os conceitos possam ser introduzidos também de forma a favorecer futuras aprendizagens. Aqui, mais uma vez, aparece a preocupação com a correção conceitual, que parece ser subordinada à e/ou contraditória com a concepção de conceito como construção, cara às perspectivas construtivistas.

Em que pese a importância das contribuições das abordagens construtivistas para repensar o ECN, é preocupante e sintomático que nos trabalhos analisados designações tais como concepções prévias, alternativas e espontâneas tenham sido usadas de forma indiscriminada, e sempre na perspectiva da superação do progresso em direção a uma formulação conceitual correta e definitiva. Dessa forma, ainda que afirmem o conhecimento científico como resultado de um processo de construção histórica, os trabalhos contribuem pouco para a ruptura de posturas naturalizadas frente aos conteúdos de ensino. Os argumentos usados para defender a inclusão e a permanência desses conteúdos no currículo atribuem determinado grau de universalidade a eles, fundamentado no privilégio epistemológico da ciência. A legitimação desses conhecimentos se realiza na medida em que são apresentados como únicos capazes de garantir a completude ausente (LACLAU, 1996) e a existência do cidadão implica a existência do não-cidadão, comprometendo a ideia de unidade da nação.

\section{Finalizando}

Para finalizar, entendo que, embora quantitativamente a produção voltada para o ECN nos níveis elementares ainda seja insuficiente, qualitativamente ela aponta tendências que permitem caracterizar, em linhas gerais, o discurso que está sendo produzido sobre o que pode ser considerado um ECN “mais adequado". São sentidos que circulam, não ficam restritos aos textos oficiais ou aos discursos dos pesquisadores e 
especialistas da área, mas se disseminam socialmente, influenciando o contexto da prática. Esse discurso se fundamenta em uma concepção de currículo como artefato tal qual está nos fundamentos da racionalidade, que organiza o processo de seleção dos conteúdos escolares na modernidade. Um currículo legitimado com base na possibilidade de uma descrição objetiva dos fatos, capaz de garantir a objetividade do conhecimento, que se entende universal.

Nessa perspectiva, o currículo concebido "como um pacote 'lançado de cima para baixo' [grifo da autora] nas escolas, determinado pelos governos, cabendo às escolas apenas implementar ou resistir a esse pacote" (LOPES, 2006, p. 39). Dessa forma, as análises sobre o que realmente acontece nas salas de aula perdem a capacidade de apreender o dinamismo do currículo, que se realiza como processo de reinterpretação em que são incorporados significados múltiplos e diferenciados, dado que se encontra aberto a influências diversas que não podem ser prévia e definitivamente determinadas.

Assim, embora venham se constituindo como hegemônicos, esses discursos não dão conta de expressar aquilo que o ECN é em sua totalidade e diversidade. Pelo contrário, na perspectiva em que me situo, entendo ser mais produtivo pensá-lo como processo de permanente ressignificação e, dessa forma, buscar compreender os discursos híbridos presentes nos diferentes contextos de produção curricular.

Como foi esclarecido inicialmente, este artigo teve como objetivo apresentar parte dos resultados e das análises de uma investigação mais ampla que tem por fundamento a concepção de currículo como discurso produtor de sentidos. Dessa forma, a análise das produções dos ENPECs tem sido produtiva menos para avaliar as propostas e concepções que apresentam e mais porque permitem compreender a concepção de currículo que as orienta. A concepção de currículo como artefato produzido fora da escola e que por ela deve ser implementado favorece uma leitura da prática como mero local de resistência, como lugar em que as "boas" propostas são transgredidas. Ou ainda, como afirmam Oliveira e Diniz (2009), analisando o discurso de professoras-alunas do curso de Pedagogia, como lugar em que um discurso sobre o ensino de ciências, assumido de forma pouco crítica, produz um ensino contraditório, que contribui pouco para a compreensão da complexidade que envolve o processo. Por isso, mesmo que na maioria dos textos analisados o saber 
docente seja assumido como saber prático que implica um processo de reflexão. A especificidade do trabalho docente é afirmada como atividade que pressupõe refletir sobre a ação, o que exige a formação de um professor reflexivo, capaz de criar situações de ensino problematizadoras, em que conceitos científicos possam ser apropriados pelas crianças. Poucas referências aparecem sobre as finalidades específicas da escolarização nos anos iniciais do EF, muitas para além dos limites restritos dos processos de ensino, que justificariam o ensino desses conteúdos. Sem a definição dessas finalidades, a avaliação do trabalho realizado fica comprometida.

Por outro lado, é preciso considerar que o discurso que anuncia como deveria ser o ECN, para dar conta das demandas de uma educação de qualidade, apresenta propostas que não são desconhecidas das professoras que atuam nos anos iniciais do EF e nem estranhas ao cotidiano das escolas. A questão crucial é que esse discurso - que propaga uma proposta curricular - , assim como qualquer outro, não pode dar conta de fixar e controlar a emergência de sentidos atribuídos ao ensino da ciência em cada contexto específico em que esses conteúdos são desenvolvidos. Essa compreensão pode favorecer uma postura mais otimista e mais produtiva para, garantindo o atendimento às especificidades locais, operarmos para potencializar todas as iniciativas que possam contribuir para a construção de uma qualidade possível.

Assim, sem a intenção de minimizar o necessário investimento em formação docente, é preciso considerar que, muitas vezes, nas aulas de ciências dos anos iniciais, o uso do conceito "cientificamente correto" não atende às demandas de ensino e de aprendizagem e/ou de outras tantas demandas que emergem no cotidiano das escolas. 


\section{REFERÊNCIAS}

AZEVEDO, Rosa Oliveira M; GHENDIN, Evandro; GONZAGA, Amarildo M. Conceitos teóricos-epistemológicos na formação de professores para o ensino de ciências nos anos iniciais do ensino fundamental. In: ENCONTRO NACIONAL DE PESQUISA EM EDUCAÇÃO EM CIÊNCIAS, 6, 2007, Florianópolis, Anais. Belo Horizonte: FAE/UFMG, 2008. 1 CD-ROM.

BACCI, Denise de La Corte; Criscuolo, Cristina. Imagens de satélite na escola: uma perspectiva para a percepção ambiental na construção do conhecimento. In: ENCONTRO NACIONAL DE PESQUISA EM EDUCAÇÃO EM CIÊNNCIAS, 6, 2007, Florianópolis, Anais. Belo Horizonte: FAE/UFMG, 2008. 1 CD-ROM.

BALL, Stephen J. Educational reform: a critical and post-structural approach. Buckingham: Open University Press, 1994.

BALL, Stephen J. Diretrizes políticas globais e relações políticas locais em Educação. Currículo sem fronteiras. v. 1, n. 2, p. 99-116, dez. 2001. Disponível em: <htpp:www.vol1iss2articles/ball.pdf>. Acesso em: 23 jul. 2009.

BARREIROS, Débora R. Alves. Todos iguais...Todos diferentes... Problematizando os discursos que constituem a prática curricular da Secretaria Municiapal de Educação do rio de Janeiro (SME/RJ). 2009. 231f. Tese (Doutorado em Educação) - Faculdade de Educação, Universidade do Estado do Rio de Janeiro, Rio de Janeiro, 2009.

BASTOS, Fernando. Fatores e estratégias que influenciam o desenvolvimento de ações de formação de professores na área do ensino de Ciências: um estudo focalizando a Educação Infantil. In: ENCONTRO NACIONAL DE PESQUISA EM EDUCAÇÃO EM CIÊNCIAS, 7, Florianópolis, 2009. Disponível em: <http://www.foco.fae.ufmg.br/viienpec/index.php/enpec/viienpec/paper/viewFile/2 89/478>. Acesso em: 6 fev. 2010.

BIZERRA, Alessandra et al. Crianças pequenas e seus conhecimentos sobre microrganismos. In: ENCONTRO NACIONAL DE PESQUISA EM EDUCAÇÃO EM CIÊNCIAS, 7, Florianópolis, 2009. Disponível em: <http://www.foco.fae.ufmg.br/viienpec/index.php/enpec/viienpec/paper/viewFile/4 72/482>. Acesso em: 6 fev. 2010.

BOWE, R. et al. Reforming education \& changing schools: case studies in policy sociology. London: Routledge, 1992.

BRANDO, Fernanda da Rocha; ANDRADE, Mariana A. B. Soares de; MARQUES, Deividi Márcio. Formação de professores de Educação Infantil para o ensino de Ciências. In: ENCONTRO NACIONAL DE PESQUISA EM EDUCAÇÃO EM CIÊNCIAS, 6, 2007, Florianópolis, Anais. Belo Horizonte: FAE/UFMG, 2008. 1 CDROM.

BURITY, Joanildo Albuquerque. Discurso, política e sujeito na teoria da hegemonia de Ernesto Laclau. In: MENDONÇA, Daniel de; RODRIGUES, Léo Peixoto (Orgs.). PósEstruturalismo e Teoria do Discurso: em torno de Ernesto Laclau. Porto alegre: EDIPUCRS, 2008, p. 35-51.

CARNEIRO, Marcos Antônio B.; ARAÚJO, Mônica 1. Falena; OLIVEIRA, Maria Marly de. Análise dos ecossistemas costeiros dos municípios de Itapissuma/Itamarcá-PE e seus problemas ambientais através de trilhas ecológicas e contextualizados no ensino de 
Ciências. In: ENCONTRO NACIONAL DE PESQUISA EM EDUCAÇÃO EM CIÊNCIAS, 6, 2007, Florianópolis, Anais. Belo Horizonte: FAE/UFMG, 2008. 1 CDROM.

DIAS, Rosanne Evangelista. Ciclo de politicas curriculares na formação de professores no Brasil (1996-2006). 2009, 248 f. Tese (Doutorado em Educação) - Faculdade de Educação, Universidade do Estado do Rio de Janeiro, Rio de Janeiro, 2009.

FERREIRA JUNIOR, Milton B. et al. Capacitando e acompanhando pedagogos em aulas de Ciências. In: ENCONTRO NACIONAL DE PESQUISA EM EDUCAÇ̃̃O EM CIÊNCIAS, 6, 2007, Florianópolis, Anais. Belo Horizonte: FAE/UFMG, 2008. 1 CD-ROM.

FERNANDES, Rebeca Chiacchio Azevedo; MEGID NETO, Jorge. Modelos educacionais nas pesquisas sobre práticas pedagógicas no ensino de Ciências nos anos iniciais da escolarização (1972-2005). In: ENCONTRO NACIONAL DE PESQUISA EM EDUCAÇÃO EM CIÊNCIAS, 7, Florianópolis, 2009. Disponível em: <http://www.foco.fae.ufmg.br/viienpec/index.php/enpec/viienpec/paper/viewFile/1 395/218>. Acesso em: 6 fev. 2010.

FREIRE, Cecília Yoshida; TRIVELATO, Sílvia Luzia Frateschi. Um levantamento das orientações da rede municipal de ensino de São Paulo - um enfoque para o ensino de Ciências. In: ENCONTRO NACIONAL DE PESQUISA EM EDUCAÇÃO EM CIÊNCIAS, 2, 1999, Valinhos- SP, Anais. Florianópolis: OPM CED/UFSC, 1999. 1 CDROM.

KRASILCHIK, Mírian. Reformas e realidade: o caso do ensino das ciências. São Paulo Perspectiva, São Paulo, n. 14(1), p. 85-93, 2000. Disponível em: <http://www.scielo.br/pdf/spp/v14n1/9805.pdf>. Acesso em: 15 dez. 2003.

LACLAU, Ernesto. Misticismo, retórica y politica. Buenos Aires: Fondo de Cultura Econômica, 2006.

LACLAU, Ernesto. La razón populista. Buenos Aires: Fondo de Cultura Econômica, 2005. LACLAU, Ernesto. Universalismo, particularismo e a questão da identidade. In: MENDES, Cândido (Coord.). Pluralismo cultural, identidade e globalizaçãa. Rio de Janeiro: Record, 2001, p. 229-250.

LACLAU, Ernesto. Desconstrução, pragmatismo, hegemonia. In: MOUFFLE, Chantal. (Edit). Desconstrución y pragmatismo. Buenos Aires: Paidós, 1998, p. 97-136.

LACLAU, Ernesto; MOUFFE, Chantal. Hegemonía y estrategia socialista. Buenos Aires: Fondo de cultura económica, 2004.

LEAL, Maria Cristina; GOUVÊA, Guaracira. Ensino de Ciências e Ciência tecnologia e Sociedade: comparando perspectivas no ensino formal e não-formal. ENCONTRO NACIONAL DE PESQUISA EM EDUCAÇÃO EM CIÊNCIAS, 2, 1999, ValinhosSP, Anais. Florianópolis: OPM CED/UFSC, 1999. 1 CD-ROM.

LONGHINI, Marcos Daniel. MORA, Iara Maria. A natureza do conhecimento científico nas aulas de Ciências nos anos iniciais do ensino fundamental. In: ENCONTRO NACIONAL DE PESQUISA EM EDUCAÇÃO EM CIÊNCIAS, 7, Florianópolis, 2009. Disponível em: <http://www.foco.fae.ufmg.br/viienpec/index.php/enpec/viienpec/paper/viewFile/245/3>. Acesso em: 6 fev. 2010.

LOPES, Alice Casimiro. Políticas de integração curricular. Rio de Janeiro: UERJ, 2008.

LOPES, Alice Casimiro. Discursos nas políticas de currículo. Currículo sem Fronteiras, v. 6, 
n. 2, p. 33-52, jul/dez. 2006. Disponível em:

$<$ http://www.curriculosemfronteiras.org/vol6iss2articles/lopes.pdf >. Acesso em: 20 maio 2008.

LOPES, Alice Casimiro. Políticas de currículo: tensões entre recontextualização e hibridismo. Currículo sem fronteiras, v. 5, n. 2, p. 50-64, jul./dez. 2005. Disponível em: $<$ http://www.curriculosemfronteiras.org/vol5iss2articles/lopes.htm>. Acesso em: 30 mar. 2008.

LOPES, Alice Casimiro. Políticas de currículo: mediação por grupos disciplinares de ensino de Ciências e Matemática. In: LOPES, Alice R. C \& MACEDO, Elizabeth. Currículo de Ciências em debate. São Paulo: Papirus, 2004, p. 45-75.

LOPES, Alice Casimiro. Conhecimento escolar: ciência e cotidiano. Rio de Janeiro: UERJ, 1999.

MACEDO, Elizabeth F. Que queremos dizer com Educação para a cidadania? In: LOPES et al (Orgs.) Politicas Educativas e dinâmicas curriculares no Brasil e em Portugal. Petrópolis: DP et Alii; Rio de Janeiro: FAPERJ, 2008, p. 89-114.

MACEDO, Elizabeth F. Currículo e hibridismo: para politizar o currículo como cultura. Educação em Foco - Questões Contemporâneas de Currículo, v. 8, n. 1 e 2, p. 13-30, mar/ago 2003, set/fev 2003/2004.

MEGID NETO, Jorge. O que sabemos sobre a Pesquisa em ensino de Ciências no nível fundamental: tendências de teses e dissertações defendidas entre 1972 e 1995. In: ENCONTRO NACIONAL DE PESQUISA EM EDUCAÇ̃̃O EM CIÊNCIAS, 2, 1999, Valinhos- SP, Anais. Florianópolis: OPM CED/UFSC, 1999. 1 CD-ROM.

MENDES SOBRINHO, José Augusto de C. Aspectos Históricos do ensino de Ciências no curso de Magistério. ENCONTRO NACIONAL DE PESQUISA EM EDUCAÇÃO EM CIÊNCIAS, 1, 1997, Águas de Lindóia- SP, Anais. 1 CD-ROM.

MENDONÇA, Daniel de. A noção de antagonismo na ciência política contemporânea: uma análise a partir da perspectiva da teoria do discurso. Rev. Sociol. Polit., Curitiba, 20, p. 135-145, jun. 2003. Disponível em: <http://www.scielo.br/pdf/rsocp/n20/n20a11.pdf.> Acesso em: 12 dez. 2008.

MOREIRA, A. F. Barbosa. Os parâmetros curriculares em questão. Educação \& Realidade, Porto Alegre, v. 21, n. 1, p. 9-22, jan/jun. 1996.

OLIVEIRA, Leandra Martins et al. A Educação tecnológica no contexto das séries iniciais do EF: a voz docente. In: ENCONTRO NACIONAL DE PESQUISA EM EDUCAÇÃO EM CIÊNCIAS, 6, 2007, Florianópolis, Anais. Belo Horizonte: FAE/UFMG, 2008. 1 CD-ROM.

OLIVEIRA, Rosemary Rodrigues de; DINIZ, Renato Eugênio da Silva. O ensino de Ciências nas séries iniciais do Ensino Fundamental: compreendendo discursos de professoras-alunas. In: ENCONTRO NACIONAL DE PESQUISA EM EDUCAÇÃO EM CIÊNCIAS, 7, Florianópolis, 2009. Disponível em: <http://www.foco.fae.ufmg.br/viienpec/index.php/enpec/viienpec/paper/viewFile/2 45/3>. Acesso em: 6 fev. 2010.

PAVAN, Francine; BRASIL, Josiely N.; TERRAZZAN, Eduardo A. O que se tem e o que se pode fazer com relação a alfabetização científica e tecnológica nos anos iniciais. In: ENCONTRO NACIONAL DE PESQUISA EM EDUCAÇÃO EM CIÊNCIAS, 6, 2007, Florianópolis, Anais. Belo Horizonte: FAE/UFMG, 2008. 1 CD-ROM.

Educação em Revista | Belo Horizonte | v.27 | n.02 | p.151-176 | ago. 2011 
PEREIRA, Talita Vidal. As contribuições do paradigma pós-estruturalista para analisar as políticas curriculares. Espaço do Currículo [On line] Revista da Universidade Federal da Paraíba, João Pessoa, v. 3, n. 1, p. 419-430, mar./set. 2010. Disponível em:<http://periodicos.ufpb.br/ojs2/index.php/rec>. Acesso em: 10 jan. 2011.

PORTELA, Caroline Dorada P.; HIGA, Ivanilda. Os estudos sobre ensino de Física nas séries iniciais do Ensino Fundamental. In: ENCONTRO NACIONAL DE PESQUISA EM EDUCAÇÃO EM CIÊNCIAS, 6, 2007, Florianópolis, Anais. Belo Horizonte: FAE/UFMG, 2008. 1 CD-ROM.

RAZERA, Júlio C. C. et al. Aspectos do conceito de vacina nos livros didáticos do ensino Fundamental. ENCONTRO NACIONAL DE PESQUISA EM EDUCAÇÃO EM CIÊNCIAS, 2, 1999, Valinhos- SP, Anais. Florianópolis: OPM CED/UFSC, 1999. 1 CDROM.

ROCHA, Maína Bertagna; MEGID NETO, Jorge. Práticas de formação de professores para o ensino de Ciências nas séries iniciais do Ensino Fundamental. In: ENCONTRO NACIONAL DE PESQUISA EM EDUCAÇÃO EM CIÊNCIAS, 7, Florianópolis, 2009. Disponível em: <http://www.foco.fae.ufmg.br/viienpec/index.php/enpec/viienpec/paper/viewFile/1333/165>. Acesso em 6 fev. 2010.

SACRISTÁN. J. Gimeno. A cultura para os sujeitos ou os sujeitos para a cultura? O mapa mutante dos conteúdos na escolaridade. In: SACRISTÁN. J. Gimeno. Poderes instáveis em Educação. Porto Alegre: Artmed, 1999, p. 147-206.

SASSERON, Lúcia Helena; CARVALHO, Anna M. Pessoa. Ensino por CTSA: almejando a alfabetização científica no ensino Fundamental. In: ENCONTRO NACIONAL DE PESQUISA EM EDUCAÇÃO EM CIÊNCIAS, 6, 2007, Florianópolis, Anais. Belo Horizonte: FAE/UFMG, 2008. 1 CD-ROM.

SILVA, Aparecida de Fátima A. da; MARCONDES, Maria Eunice R. Ensino e aprendizagem de Ciências nas séries iniciais concepções de um grupo de professores em formação. In: ENCONTRO NACIONAL DE PESQUISA EM EDUCAÇÃO EM CIÊNCIAS, 6, 2007, Florianópolis, Anais. Belo Horizonte: FAE/UFMG, 2008. 1 CDROM.

VERASZTO, Estéfano et al. Projeto Teckids: levando a Educação tecnológica para o ensino fundamental. In: ENCONTRO NACIONAL DE PESQUISA EM EDUCAÇÃO EM CIÊNCIAS, 6, 2007, Florianópolis, Anais. Belo Horizonte: FAE/UFMG, 2008. 1 CD-ROM.

WORTMAN, Maria Lúcia Castagna. Currículo e Ciências - as especificidades pedagógicas do ensino de Ciências. In: COSTA, Marisa Voraber. O currículo nos limiares do contemporâneo. Rio de Janeiro: DP\&A, 1998, p. 129-157.

ZANON, Lenir Basso; CARDINAL, Daiane. O conceito substância na exploração do tema cárie dentária no ensino fundamental. ENCONTRO NACIONAL DE PESQUISA EM EDUCAÇÃO EM CIÊNCIAS, 2, 1999, Valinhos- SP, Anais. Florianópolis: OPM CED/UFSC, 1999. 1 CD-ROM.

ZIBAS, Dagmar M. L. A reforma do ensino médio nos anos de 1990: o parto da montanha e as novas perspectivas. Revi. Bras. Educ. [online]. 2005, n. 28, p. 24-36. Disponível em: <http: / / www.scielo.br/scielo.php? script=sci_arttext\&pid $=$ S141324782005000100003\&lng=pt\&nrm=iso\&tlng=pt>. Acesso em: 10 out. 2010. 


\section{NOTAS}

1 A opção pela designação no substantivo feminino foi feita em função de contatos com o campo de pesquisa que confirmam que as mulheres são a imensa maioria dos profissionais atuantes nesse nível de ensino.

2 A ideia dos diferentes contextos de produção curricular é tomada da abordagem do ciclo contínuo de política desenvolvido por Bowe e colaboradores (1992). No trabalho, são apresentados três contextos em que as políticas são produzidas continuamente: o de influência, o de produção de texto e o contexto da prática.

3 Em http://www.foco.fae.ufmg.br/viienpec/index.php/enpec/viienpec

4 Os anais do VI ENPEC realizado em 2007 foram divulgados em CD-Rom, em 2008.

5 ALMEIDA, Maria A. V. de et al. Entre o sonho e a realidade: comparando concepções de professores de $1^{\mathrm{a}}$ a $4^{\mathrm{a}}$ séries sobre ensino de ciências com a proposta dos PCNs. Revista Brasileira de Pesquisa em Educação em Ciências, v. 1, n. 2, p. 109-119, 2001.

6 Com a expansão dos anos de escolaridade no ensino fundamental, a quarta série passou a ser equivalente ao quinto ano.

Recebido: $30 / 04 / 2010$

Aprovado: 23/03/2011

Contato:

Faculdade de Educação

Faculdade de Educação
Rua São Francisco Xavier, $524 \cdot 12^{\circ}$ andar

Maracanã

CEP 20550-900

Rio de Janeiro, RJ

Brasil 
